\title{
Rising cesarean deliveries among apparently low-risk mothers at university teaching hospitals in Jordan: analysis of population survey data, 2002-2012
}

\author{
Rami Al Rifai ${ }^{a}$
}

Cesarean deliveries nationally in Jordan have increased to $30 \%$, including substantial increases among births that are likely low risk for cesarean delivery for the most part. This level is double the threshold that WHO considers reasonable.

\begin{abstract}
Background: Cesarean delivery conducted without medical indication places mothers and infants at risk for adverse outcomes. This study assessed changes in trends of, and factors associated with, cesarean deliveries in Jordan, from 2002 to 2012.

Methods: Data for ever-married women ages 15-49 years from the 2002, 2007, and 2012 Jordan Population and Family Health Surveys were used. Analyses were restricted to mothers who responded to a question regarding the hospital-based mode of delivery for their last birth occurring within the 5 years preceding each survey $(2002, N=3,450$; 2007, $N=6,307 ; 2012, N=6,365)$. Normal birth weight infants and singleton births were used as markers for births that were potentially low risk for cesarean delivery, because low/high birth weight and multiple births are among the main obstetric variables that have been documented to increase risk of cesareans. Weighted descriptive and multivariate analyses were conducted using 4 logistic regression models: (1) among all mothers; and among mothers stratified (2) by place of delivery; (3) by birth weight of infants; and (4) by singleton vs. multiple births.

Results: The cesarean delivery rate increased significantly over time, from $18.2 \%$ in 2002 , to $20.1 \%$ in 2007 , to $30.3 \%$ in 2012. Place of delivery, birth weight, and birth multiplicity were significantly associated with cesarean delivery after adjusting for confounding factors. Between 2002 and 2012, the rate increased by $99 \%$ in public hospitals vs. $70 \%$ in private hospitals; by $93 \%$ among normal birth weight infants vs. $73 \%$ among low/high birth weight infants; and by $92 \%$ among singleton births vs. $29 \%$ among multiple births. The changes were significant across all categories except among multiple births. Further stratification revealed that the cesarean delivery rate was 2.29 times higher in university teaching hospitals (UTHs) than in private hospitals $(P<.001)$, and 2.31 times higher than in government hospitals $(P<.001)$. Moreover, in $\mathrm{UTH}$ s, the rate was higher among normal birth weight infants (adjusted $O R=2.15$ ) and singleton births (adjusted $O R=2.39$ ). Conclusion: The rising cesarean delivery rate among births that may have been at low risk for cesarean delivery, particularly in UTHs, indicates that many cesarean deliveries may increasingly be performed without any medical indication. More vigilant monitoring of data from routine health information systems is needed to reduce unnecessary cesarean deliveries in apparently low-risk groups.
\end{abstract}

\section{INTRODUCTION}

W orldwide, cesarean delivery is one of the most common surgeries performed in modern obstetrics. ${ }^{1}$ The surgery is intended to save the lives of mothers and newborns, as in cases of dystocia, breech presentation, multiple births, anticipated low/high

\footnotetext{
${ }^{a}$ Graduate School of Tokyo Medical and Dental University, Division of Public Health, Department of International Health and Medicine, Tokyo, Japan.

Correspondence to Rami Al Rifai (alrifai.ith@łmd.ac.jp).
}

birth weight, and fetal distress. ${ }^{2,3}$ But cesarean deliveries conducted without any medical indication place mothers and infants at risk for unfavorable outcomes. For example, compared with vaginal delivery, cesarean delivery is associated with increased risk of blood transfusion, hysterectomy, maternal and child death, ${ }^{4-6}$ uterine rupture, placenta accreta, and placenta previa in a subsequent pregnancy. ${ }^{7,8}$ In addition, cesarean deliveries cost more and require longer hospitalization than vaginal deliveries. ${ }^{9}$ 


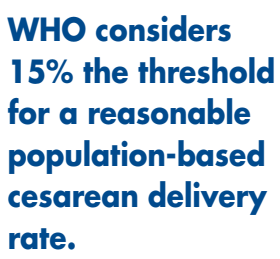

The World Health Organization (WHO) considers a population-based rate of cesarean deliveries over $15 \%$ unreasonable. ${ }^{10}$ A recent study found that half of 137 countries have exceeded this recommended threshold. ${ }^{11}$ A global survey conducted by WHO in 24 countries over 25 years showed that about $26 \%$ of all health facility-based deliveries were cesarean, and in 23 countries, rates of cesarean delivery without medical indication ranged between $0.01 \%$ and $2 \%{ }^{5}$ In Jordan, the last study examining trends in cesarean delivery rates using population-based data revealed a consistent increase in the rate. ${ }^{12}$

Jordan has one of the most modern health care infrastructures in the Middle East. The health system consists of 3 major sectors-public, private, and donors-that cover primary, secondary, and tertiary health care services. The public sector consists of health facilities governed by the Ministry of Health $(\mathrm{MOH})$, Royal Medical Services (RMS), and University Teaching Hospitals (UTHs). ${ }^{13}$ Only tertiary health care facilities (hospitals) have the capacity to perform major surgical procedures such as cesarean deliveries.

According to the Jordan Population and Family Health Survey (JPFHS), almost all women (99\%) in the country receive antenatal care (ANC) from a skilled provider, most commonly from a doctor (96\%). Nearly all women (91\%) have an ANC visit before their fourth month of pregnancy, and $78 \%$ of women make 7 or more ANC visits throughout their pregnancy. ${ }^{14}$ Virtually all births (99\%) occur in a health facility; 3 births of every 4 are delivered by a doctor, and 1 birth of every 4, by a nurse or midwife. ${ }^{14}$ The maternal mortality ratio increased from 53 maternal deaths per 100,000 live births in 2008 to $63 / 100,000$ in 2010 , while the neonatal mortality rate persisted at rate of 12 deaths/1,000 live births between 2009 and 2013. ${ }^{15,16}$

The objectives of this study were to examine trends in, and factors associated with, cesarean deliveries in Jordan, from 2002 to 2012, using data from nationally representative surveys of ever-married women ages 15-49 years.

\section{METHODS}

\section{Data Source and Sampling}

This study used nationally representative data from the 2002, 2007, and 2012 JPFHS, which is part of the worldwide Demographic and Health Surveys (DHS) program. ${ }^{14}$

In total, 28,234 ever-married women ages 15-49 years participated in the 3 JPFHS survey rounds (Figure). Women who did not report giving birth over the prior 5 years or who reported that they delivered their last birth at home or abroad were excluded, resulting in a final sample of 16,774 women, or a weighted sample of 16,122 women $(3,450$ from the 2002 survey; 6,307 from 2007; and 6,365 from 2012).

\section{Measurements}

\section{Outcome Variable}

The outcome of interest was hospital-based mode of delivery for the last birth; cesarean delivery was reported as a binary response (yes/no).

\section{Sociodemographic Variables}

The analysis included information about different sociodemographic characteristics that may be associated with cesarean delivery:

- Woman's age reported in 5 groups (15-19, 20-24, 25-29, and $\geq 30$ years)

- Place of residence (urban/rural)

- Geographic region (central, north, or south)

- Mother's and partner's education level (no education, primary, secondary, or higher education)

- Employment status (mothers with any income-producing profession were reported as employed)

- Place of delivery (public hospitals governed by the MOH, RMS, or UTHs, or private hospitals)

- Wealth index constructed using data on household assets and categorized into quintiles (poorest, poorer, middle, richer, and richest) ${ }^{14,17}$

\section{Obstetric Variables}

- Mother's age at first birth was reported in 4 groups: 12-18, 19-24, 25-30, or $>30$ years.

- Parity was reported in 3 groups: 1, 2, or 3 or more children.

- Since low or high birth weight and multiple births are among the main obstetric variables documented in the literature to increase risk of cesarean delivery, ${ }^{12,18,19}$ these 2 variables were used in this analysis as markers for births that were potentially at low risk for cesarean delivery (while recognizing that this may not always be the case). Women who delivered either singleton or normal birth weight infants $(2,500$ to 3,999 grams) were categorized as low risk for cesarean delivery while women who delivered either multiple or low/high birth 
weight infants $(<2,500$ grams or $\geq 4,000$ grams) were categorized as high risk. ${ }^{12}$

\section{Statistical Analysis}

Frequencies and percentages for each measured characteristic by year of survey were recorded. Rates of cesarean delivery for the last birth born within the 5 years prior to the survey were compared between the 2002, 2007, and 2012 surveys, and the potential difference in the cesarean rate for each measured variable was evaluated for each survey, separately, by using chi-square tests.

To document trends in the cesarean rate over a period of 10 years, the first survey conducted in 2002 was set as a reference in 4 binary logistic regression models, which estimated odds ratios (ORs) and adjusted odds ratios (aORs) as well as 95\% confidence intervals (CIs) for significance testing. The first model was run among all mothers together and the other 3 models were run for mothers stratified by: (1) place of delivery (public or private), (2) birth weights, and (3) birth multiplicity (singleton vs. multiple births).

To assess whether place of delivery was associated with changes in trends of cesarean deliveries, all subjects were further stratified according to birth weights and birth multiplicity in public and private hospitals, separately, as well as by type of public hospital (government hospitals vs. UTHs) for those who reported delivering in a public hospital. In order to control for potential confounding effects, even when there was no association with cesarean delivery, all covariates under analysis (sociodemographic and obstetric) were entered simultaneously in the multivariate logistic regression models.

Logistic regression models were also used to assess the association between measured covariates with cesarean delivery and to investigate the independent association of the year of the survey on cesarean delivery after merging the 3 datasets. $P$ value for the trend was assessed for each model by entering the year of the survey as a continuous variable. $^{20}$ All analyses were conducted using SPSS version 18.0. The level of statistical significance for all analysis was set at $\alpha=.05$.

\section{RESULTS}

\section{Descriptive Profile of the Mothers}

Overall, $57.4 \%$ of mothers in the 3 datasets combined were $\geq 30$ years old. The majority lived in urban areas and had secondary or higher education. In $2002,10.1 \%$ of the mothers were employed compared with $15.5 \%$ in 2012 (Table 1).

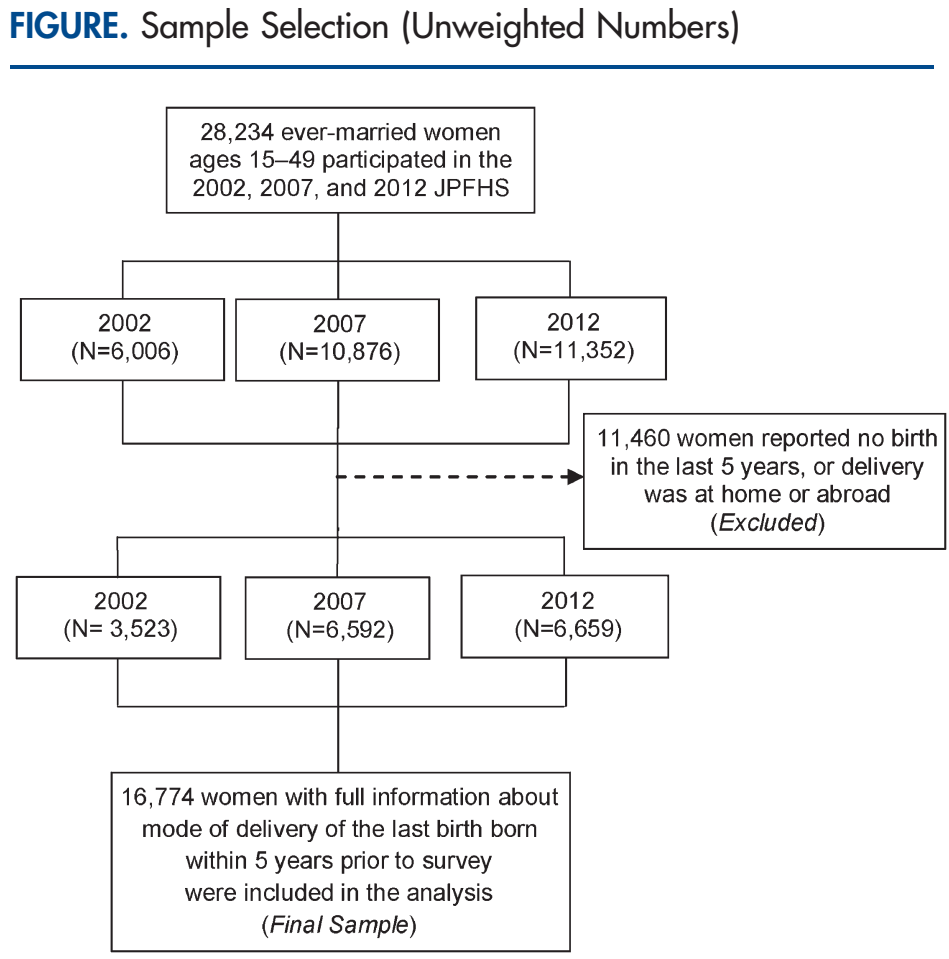

Abbreviation: JPFHS, Jordan Population and Family Health Survey.

Approximately two-thirds (65.1\%) of deliveries were in public hospitals with no significant changes in that percentage over the study period. The percentage of women belonging to poor ("poorest" and "poorer") households declined by 8.5 percentage points between 2002 and 2012, with a corresponding 5.2 percentage point increase in those belonging to rich households ("richer" and "richest").

First birth occurred at age 19-24 years among $58.5 \%$ of mothers, and most had 1 or 2 children. From 2002 to 2012, there was no significant change in the percentage of mothers reporting low/high birth weight infants or multiple births.

\section{Trends in the Cesarean Delivery Rate}

The cesarean delivery rate increased over time, The cesarean from $18.2 \%$ in 2002 to $30.3 \%$ in 2012 (Table 2 ). delivery rate in Between 2007 and 2012, the rate increased by Jordan increased 10.2 percentage points compared with an increase from $\mathbf{1 8 \%}$ in $\mathbf{2 0 0 2}$ of only 1.9 percentage points from 2002 to 2007.

Age, mother's education, and place of delivery persisted as significant factors in the cesarean delivery rate during each survey round $(P<.05$ 
TABLE 1. Background Characteristics of Survey Respondents by Year of Survey, Weighted Numbers (Percentages)

\begin{tabular}{llll}
\hline Characteristics & $2002(\mathrm{~N}=3,450)$ & $2007(\mathrm{~N}=6,307)$ & $2012(\mathrm{~N}=6,365)$ \\
\hline
\end{tabular}

\section{SOCIODEMOGRAPHIC}

Age, $y$

$$
\begin{aligned}
& 15-19 \\
& 20-24 \\
& 25-29 \\
& \geq 30
\end{aligned}
$$

$55(1.6)$
$515(14.9)$
$884(25.6)$
$1997(57.9)$

$$
\begin{gathered}
123(1.9) \\
974(15.4) \\
1654(26.2) \\
3556(56.4)
\end{gathered}
$$$$
135(2.1)
$$$$
854(13.4)
$$$$
1669(26.2)
$$$$
3707 \text { (58.2) }
$$

Place of Residence

$$
\begin{aligned}
& \text { Urban } \\
& \text { Rural }
\end{aligned}
$$$$
2705(78.4)
$$$$
5298(84.0)
$$$$
5198 \text { (81.7) }
$$$$
746 \text { (21.6) }
$$$$
1009(16.0)
$$$$
1167 \text { (18.3) }
$$

Geographic Region

Central

North

South

Mother's Education

No education

Primary

Secondary

Higher

Husband's Education

No education

Primary

Secondary

Higher

$$
\begin{gathered}
2191(63.5) \\
930(27.0) \\
329(9.5)
\end{gathered}
$$

128 (3.7)

$277(8.0)$

2087 (60.5)

959 (27.8)

$$
65 \text { (1.9) }
$$

371 (10.8)

1980 (57.4)

1034 (30.0)

Missing (Do not know)

Employment

Unemployed

Employed

3101 (89.9)

350 (10.1)

Place of Delivery

Public sector

2229 (64.6)

1221 (35.4)

Private sector
$3908(62.0)$

3935 (61.8)

1844 (29.2)

555 (8.8)

$1821(28.6)$

609 (9.6)

147 (2.3)

$114(1.8)$

337 (5.3)

373 (5.9)

3885 (61.6)

3825 (60.1)

1939 (30.7)

2053 (32.2)

91 (1.5)

$59(0.9)$

665 (10.6)

661 (10.4)

$3793(60.3)$

4000 (62.8)

1745 (27.7)

$1645(25.8)$

$12(0.2)$

$1(0.02)$

$5526(87.6)$

5381 (84.5)

781 (12.4)

985 (15.5)
$4036(64.0)$

4230 (66.5)

$2271(36.0)$

\section{$(221(35.4)$}


TABLE 1 (continued).

\begin{tabular}{|c|c|c|c|}
\hline Characteristics & $2002(\mathrm{~N}=3,450)$ & $2007(N=6,307)$ & $2012(\mathrm{~N}=6,365)$ \\
\hline \multicolumn{4}{|l|}{ Wealth Index } \\
\hline Poorest & $786(22.8)$ & $1462(23.2)$ & $1313(20.6)$ \\
\hline Poorer & $881(25.5)$ & $1475(23.4)$ & $1365(21.4)$ \\
\hline Middle & $740(21.4)$ & $1368(21.7)$ & $1437(22.6)$ \\
\hline Richer & $594(17.2)$ & $1131(17.9)$ & $1291(20.3)$ \\
\hline Richest & $450(13.0)$ & $872(13.8)$ & $960(15.1)$ \\
\hline \multicolumn{4}{|l|}{ OBSTETRIC } \\
\hline \multicolumn{4}{|l|}{ Age at First Birth, $y$} \\
\hline $12-18$ & $687(19.9)$ & $1110(17.6)$ & $917(14.4)$ \\
\hline $19-24$ & $2010(58.3)$ & $3661(58.1)$ & $3747(58.9)$ \\
\hline $25-30$ & 645 (18.7) & $1289(20.4)$ & $1369(21.5)$ \\
\hline$>30$ & $107(3.1)$ & 246 (3.9) & $332(5.2)$ \\
\hline \multicolumn{4}{|l|}{ Parity in Last 5 Years } \\
\hline 1 & $1881(54.5)$ & $3531(56.0)$ & $3733(58.6)$ \\
\hline 2 & $1263(36.6)$ & $2254(35.7)$ & $2182(34.3)$ \\
\hline$\geq 3$ & $307(8.9)$ & $522(8.3)$ & $451(7.1)$ \\
\hline \multicolumn{4}{|l|}{ Birth Weight, g } \\
\hline Normal (2500-3999) & $2618(75.9)$ & $4916(77.9)$ & $4907(77.1)$ \\
\hline Low or High $(<2500$ or $\geq 4000)$ & $832(24.1)$ & $1391(22.1)$ & $1458(22.9)$ \\
\hline \multicolumn{4}{|l|}{ Birth Multiplicity } \\
\hline Singleton birth & $3371(97.7)$ & $6185(98.1)$ & $6225(97.8)$ \\
\hline Multiple birth & $80(2.3)$ & $123(1.9)$ & $140(2.2)$ \\
\hline
\end{tabular}

within each indicator for each year) (Table 2). The rate generally increased over time for all categories within these indicators, thus displaying similar trends $(P>.05$ for the trend over years for these indicators). The largest increases over time were observed among mothers aged 25-29 years and $\geq 30$ years and among mothers with primary education.

Mother's employment, parity, and age at first birth were also all significant factors in the cesarean delivery rate during each survey round, and the increases over time were also significant. In each category, the largest increases were among employed mothers (17.5 percentage point increase between 2002 and 2012), mothers with 3 or more children ( 23 percentage point increase), and mothers whose age at first birth was over 30 years (23 percentage point increase).

Wealth was a significant factor in the cesarean delivery rate in the 2007 and 2012 survey years. Mothers in the poor wealth categories ("poorest" and "poorer") generally had lower cesarean delivery rates than those in the rich categories ("richer" and "richest"), but the largest increase in cesarean deliveries over time was among mothers belonging to middle-income households (15.2 percentage point increase).

During the study period, the increase in the cesarean delivery rate among the normal birth weight group was the same as that of the low/high birth weight group (about a 12 percentage point increase), but the rate increased more 
TABLE 2. Cesarean Delivery Rate by Year of Survey and Background Characteristics, Weighted Percentages

\begin{tabular}{|c|c|c|c|c|c|c|c|c|}
\hline \multirow[b]{2}{*}{ Characteristics } & \multicolumn{2}{|c|}{2002} & \multicolumn{2}{|c|}{2007} & \multicolumn{2}{|c|}{2012} & \multirow{2}{*}{$\begin{array}{l}\text { Percentage } \\
\text { Point } \\
\text { Difference }^{a}\end{array}$} & \multirow{2}{*}{$\begin{array}{l}\text { P Value for } \\
\text { Trend }\end{array}$} \\
\hline & $\%$ & $P$ Value & $\%$ & $P$ Value & $\%$ & $P$ Value & & \\
\hline Overall Rate & 18.2 & & 20.1 & & 30.3 & & & \\
\hline Age, $y$ & & .001 & & $<.001$ & & $<.001$ & & .53 \\
\hline $15-19$ & 14.5 & & 20.3 & & 22.2 & & 7.7 & \\
\hline $20-24$ & 14.6 & & 11.1 & & 25.2 & & 10.6 & \\
\hline $25-29$ & 15.5 & & 16.9 & & 28.0 & & 12.5 & \\
\hline$\geq 30$ & 20.5 & & 24.0 & & 32.8 & & 12.3 & \\
\hline Place of Residence & & .33 & & .45 & & .12 & & .74 \\
\hline Urban & 18.6 & & 20.3 & & 30.7 & & 12.1 & \\
\hline Rural & 17.0 & & 19.2 & & 28.4 & & 11.4 & \\
\hline Geographic Region & & .008 & & .18 & & .06 & & .37 \\
\hline Central & 19.7 & & 20.2 & & 31.2 & & 11.5 & \\
\hline North & 15.1 & & 19.1 & & 28.2 & & 13.1 & \\
\hline South & 17.3 & & 22.7 & & 30.9 & & 13.6 & \\
\hline Mother's Education & & .01 & & .001 & & $<.001$ & & .75 \\
\hline No education & 22.0 & & 24.5 & & 23.5 & & 1.5 & \\
\hline Primary & 23.1 & & 24.9 & & 40.2 & & 17.1 & \\
\hline Secondary & 16.6 & & 18.6 & & 29.0 & & 12.4 & \\
\hline Higher & 19.9 & & 22.0 & & 31.3 & & 11.4 & \\
\hline Partner's Education & & .13 & & .44 & & $<.001$ & & .48 \\
\hline No education & 23.1 & & 20.7 & & 28.8 & & 5.7 & \\
\hline Primary & 16.9 & & 21.5 & & 33.0 & & 16.1 & \\
\hline Secondary & 17.3 & & 19.4 & & 28.1 & & 10.8 & \\
\hline Higher & 20.3 & & 20.9 & & 34.6 & & 14.3 & \\
\hline Employment & & .02 & & $<.001$ & & $<.001$ & & .02 \\
\hline Unemployed & 17.7 & & 19.4 & & 28.5 & & 10.8 & \\
\hline Employed & 22.6 & & 24.8 & & 40.1 & & 17.5 & \\
\hline Place of Delivery & & .004 & & .005 & & .02 & & .53 \\
\hline Public sector & 16.8 & & 19.0 & & 29.4 & & 12.6 & \\
\hline Private sector & 20.8 & & 22.0 & & 32.2 & & 11.4 & \\
\hline
\end{tabular}


TABLE 2 (continued).

\begin{tabular}{|c|c|c|c|c|c|c|c|c|}
\hline \multirow[b]{2}{*}{ Characteristics } & \multicolumn{2}{|c|}{2002} & \multicolumn{2}{|c|}{2007} & \multicolumn{2}{|c|}{2012} & \multirow{2}{*}{$\begin{array}{l}\text { Percentage } \\
\text { Point } \\
\text { Difference }^{a}\end{array}$} & \multirow{2}{*}{$\begin{array}{l}P \text { Value for } \\
\text { Trend }^{\mathrm{b}}\end{array}$} \\
\hline & $\%$ & $P$ Value & $\%$ & $P$ Value & $\%$ & $P$ Value & & \\
\hline Wealth Index & & .18 & & $<.001$ & & $<.001$ & & .47 \\
\hline Poorest & 17.4 & & 17.0 & & 28.8 & & 11.4 & \\
\hline Poorer & 16.3 & & 17.1 & & 25.4 & & 9.1 & \\
\hline Middle & 18.1 & & 19.2 & & 33.3 & & 15.2 & \\
\hline Richer & 20.0 & & 24.0 & & 31.0 & & 11.0 & \\
\hline Richest & 21.1 & & 26.5 & & 34.0 & & 12.9 & \\
\hline Parity in Last 5 Years & & $<.001$ & & .02 & & .01 & & .01 \\
\hline 1 & 20.1 & & 21.3 & & 30.0 & & 9.9 & \\
\hline 2 & 14.8 & & 18.5 & & 29.5 & & 14.7 & \\
\hline$\geq 3$ & 20.6 & & 18.4 & & 36.6 & & 16.0 & \\
\hline Age at First Birth, y & & $<.001$ & & $<.001$ & & $<.001$ & & $<.001$ \\
\hline $12-18$ & 16.9 & & 16.8 & & 24.3 & & 7.4 & \\
\hline 19-24 & 16.7 & & 17.0 & & 27.0 & & 10.3 & \\
\hline $25-30$ & 20.3 & & 28.2 & & 34.5 & & 14.2 & \\
\hline$>30$ & 43.9 & & 38.5 & & 66.9 & & 23.0 & \\
\hline Birth Weight, g & & $<.001$ & & $<.001$ & & $<.001$ & & .85 \\
\hline Normal (2500-3999) & 16.3 & & 18.1 & & 28.4 & & 12.1 & \\
\hline Low/High $(<2500$ or $\geq 4000)$ & 24.2 & & 27.1 & & 36.6 & & 12.4 & \\
\hline Birth Multiplicity & & $<.001$ & & $<.001$ & & $<.001$ & & $<.001$ \\
\hline Singleton birth & 17.3 & & 19.3 & & 29.5 & & 12.2 & \\
\hline Multiple birth & 60.0 & & 59.3 & & 65.7 & & 5.7 & \\
\hline
\end{tabular}

among singleton than among multiple births ( 12.2 percentage points vs. 5.7 percentage points, respectively; $P<.001$ ) (Table 2 ).

\section{Trends in the Cesarean Delivery Rate Stratified by Place of Delivery, Birth Weight, and Birth Multiplicity}

Place of delivery, birth weight, and birth multiplicity were significantly associated with cesarean delivery in the crude analysis and retained their statistical significance after adjustment for all covariates (Table 3). Multivariate models from the 3 combined datasets showed that the cesarean delivery rate increased significantly over time, by 13\% between 2002 and 2007, and by $90 \%$ between 2002 and $2012(P<.001)$.

Between 2002 and 2012, stratification showed that the cesarean delivery rate increased by $99 \%$ in public hospitals vs. $70 \%$ in private hospitals; the rate increased by $93 \%$ among the normal birth weight group vs. $73 \%$ among the low/high birth birth weight weight group. During the same period, the cesarean infants. 
TABLE 3. Bivariate and Multivariate Logistic Regression Analysis on Trends in the Cesarean Delivery Rate, Among All Mothers and Stratified by Place of Delivery, Birth Weight, and Birth Multiplicity According to Year of Survey

\begin{tabular}{|c|c|c|c|}
\hline & No. (\%) & OR $(95 \% \mathrm{Cl})$ & aOR $(95 \% \mathrm{Cl})$ \\
\hline \multicolumn{4}{|c|}{ Among All Mothers } \\
\hline 2002 & $629(18.2)$ & 1.00 & 1.00 \\
\hline 2007 & $1267(20.1)$ & $1.13(1.01-1.25)^{*}$ & $1.13(1.01-1.26)^{*}$ \\
\hline 2012 & $1929(30.3)$ & $1.95(1.76-2.16)^{* * *}$ & $1.90(1.71-2.11)^{* * *}$ \\
\hline \multicolumn{4}{|c|}{ By Place of Delivery } \\
\hline \multicolumn{4}{|c|}{ Public Sector } \\
\hline 2002 & 375 (16.8) & 1.00 & 1.00 \\
\hline 2007 & $768(19.0)$ & $1.16(1.01-1.33)^{*}$ & $1.15(1.00-1.33)^{*}$ \\
\hline 2012 & $1242(29.4)$ & $2.05(1.80-2.34)^{* * *}$ & $1.99(1.74-2.28)^{* * *}$ \\
\hline \multicolumn{4}{|c|}{ Private Sector } \\
\hline 2002 & $254(20.8)$ & 1.00 & 1.00 \\
\hline 2007 & $499(22.0)$ & $1.07(0.90-1.27)$ & $1.06(0.88-1.26)$ \\
\hline 2012 & $687(32.2)$ & $1.80(1.53-2.12)^{* * *}$ & $1.70(1.43-2.02)^{* * *}$ \\
\hline \multicolumn{4}{|c|}{ By Birth Weight } \\
\hline \multicolumn{4}{|l|}{ Normal } \\
\hline 2002 & 428 (16.3) & 1.00 & 1.00 \\
\hline 2007 & $890(18.1)$ & $1.13(0.99-1.28)$ & $1.11(0.98-1.26)$ \\
\hline 2012 & $1395(28.4)$ & $2.03(1.80-2.29)^{* * *}$ & $1.93(1.71-2.19)^{* * *}$ \\
\hline \multicolumn{4}{|c|}{ Low/High } \\
\hline 2002 & $201(24.2)$ & 1.00 & 1.00 \\
\hline 2007 & $377(27.1)$ & $1.17(0.96-1.42)$ & $1.13(0.93-1.39)$ \\
\hline 2012 & $534(36.6)$ & $1.81(1.50-2.20)^{* * *}$ & $1.73(1.42-2.10)^{* * *}$ \\
\hline \multicolumn{4}{|c|}{ By Birth Multiplicity } \\
\hline \multicolumn{4}{|c|}{ Singleton Birth } \\
\hline 2002 & 582 (17.3) & 1.00 & 1.00 \\
\hline 2007 & 1194 (19.3) & $1.15(1.03-1.28)^{*}$ & $1.14(1.02-1.27)^{*}$ \\
\hline 2012 & $1838(29.5)$ & $2.01(1.81-2.23)^{* * *}$ & $1.92(1.72-2.13)^{* * *}$ \\
\hline \multicolumn{4}{|c|}{ Multiple Birth } \\
\hline 2002 & $48(60.0)$ & 1.00 & 1.00 \\
\hline 2007 & $73(589.3)$ & $0.99(0.55-1.75)$ & $0.98(0.49-1.95)$ \\
\hline 2012 & $92(65.7)$ & $1.28(0.72-2.26)$ & $1.29(0.64-2.58)$ \\
\hline
\end{tabular}

Abbreviations: aOR, adjusted odds ratio (for all covariates under analysis); $\mathrm{Cl}$, confidence interval; OR, odds ratio.

$P$ value for the trend was obtained by entering the survey year as a continuous variable.

${ }^{*} P<.05 ;{ }^{* * *} P<.001$. 
delivery rate increased significantly by $92 \%$ among singleton births $(P<.001)$, whereas it increased by only $29 \%$ among multiple births $(P=.43)$.

Table 4 shows trends in cesarean deliveries among all subjects stratified by birth weight and birth multiplicity according to place of delivery. The cesarean delivery rate for mothers of normal birth weight babies in public hospitals was 2.06 times higher in 2012 than in 2002, and in private hospitals, 1.71 times higher. Similarly, the cesarean delivery rate for singleton births in public hospitals was 2.0 times higher in 2012 than in 2002, and in private hospitals, 1.76 times higher. Mothers who delivered multiple births in public hospitals were 3 times more likely to undergo cesarean delivery in 2012 than in 2002. In contrast, in private hospitals, the rate declined by $92 \%$ over time $(\mathrm{aOR}=0.08$; $P=.03)$.

Between 2002 and 2012, the cesarean delivery rate rose sharply in UTHs by 22.4 percentage points compared with increases of 11.4 and 11.9 percentage points in private and government hospitals, respectively (Table 5). Overall, the cesarean delivery rate in UTHs was 2.29 times higher than in private hospitals $(P<.001)$
The cesarean delivery rate in university teaching hospitals was more than 2 times higher than in private or government hospitals.

TABLE 4. Multivariate Logistic Regression Analysis on Trends in the Cesarean Delivery Rate by Place of Delivery, Stratified by Birth Weight and Birth Multiplicity According to Year of Survey

\begin{tabular}{|c|c|c|c|c|}
\hline & \multicolumn{2}{|c|}{$\begin{array}{l}\text { Public Hospitals } \\
\qquad(\mathrm{N}=10,496)\end{array}$} & \multicolumn{2}{|c|}{$\begin{array}{l}\text { Private Hospitals } \\
\qquad(\mathrm{N}=5,627)\end{array}$} \\
\hline & No. (\%) & aOR $(95 \% \mathrm{Cl})$ & No. (\%) & aOR $(95 \% \mathrm{Cl})$ \\
\hline \multicolumn{5}{|c|}{ By Birth Weight } \\
\hline \multicolumn{5}{|l|}{ Normal } \\
\hline 2002 & $247(14.8)$ & 1.00 & $181(19.1)$ & 1.00 \\
\hline 2007 & $525(17.0)$ & $1.17(0.99-1.39)$ & $365(19.9)$ & $1.00(0.82-1.23)$ \\
\hline 2012 & $877(27.4)$ & $2.06(1.76-2.42)^{* * *}$ & $519(30.4)$ & $1.71(1.41-2.09)^{* * *}$ \\
\hline \multicolumn{5}{|c|}{ Low/High } \\
\hline 2002 & $128(22.9)$ & 1.00 & $73(26.7)$ & 1.00 \\
\hline 2007 & $242(25.3)$ & $1.12(0.87-1.45)$ & $135(31.0)$ & $1.22(0.85-1.75)$ \\
\hline 2012 & $366(35.6)$ & $1.87(1.46-2.38)^{* * *}$ & $168(39.1)$ & $1.66(1.16-2.38)^{* *}$ \\
\hline \multicolumn{5}{|c|}{ By Birth Multiplicity } \\
\hline \multicolumn{5}{|c|}{ Singleton Birth } \\
\hline 2002 & $347(16.0)$ & 1.00 & $234(19.6)$ & 1.00 \\
\hline 2007 & $718(18.2)$ & $1.15(0.99-1.33)$ & $476(21.3)$ & $1.08(0.90-1.29)$ \\
\hline 2012 & $1171(28.3)$ & $2.00(1.74-2.29)^{* * *}$ & $667(31.8)$ & $1.76(1.47-2.09)^{* * *}$ \\
\hline \multicolumn{5}{|c|}{ Multiple Birth } \\
\hline 2002 & $28(50.9)$ & 1.00 & $20(80.0)$ & 1.00 \\
\hline 2007 & $49(60.5)$ & $1.85(0.78-4.35)$ & $23(56.1)$ & $0.32(0.05-2.09)$ \\
\hline 2012 & $72(72.0)$ & $3.05(1.27-7.33)^{*}$ & $20(50.0)$ & $0.08(0.01-0.78)^{*}$ \\
\hline
\end{tabular}

Abbreviations: aOR, adjusted odds ratio (for all covariates under analysis); $\mathrm{Cl}$, confidence interval.

$P$ value for the trend was obtained by entering the survey year as a continuous variable.

${ }^{*} P<.05 ;{ }^{* *} P<.01 ;{ }^{* * *} P<.001$. 


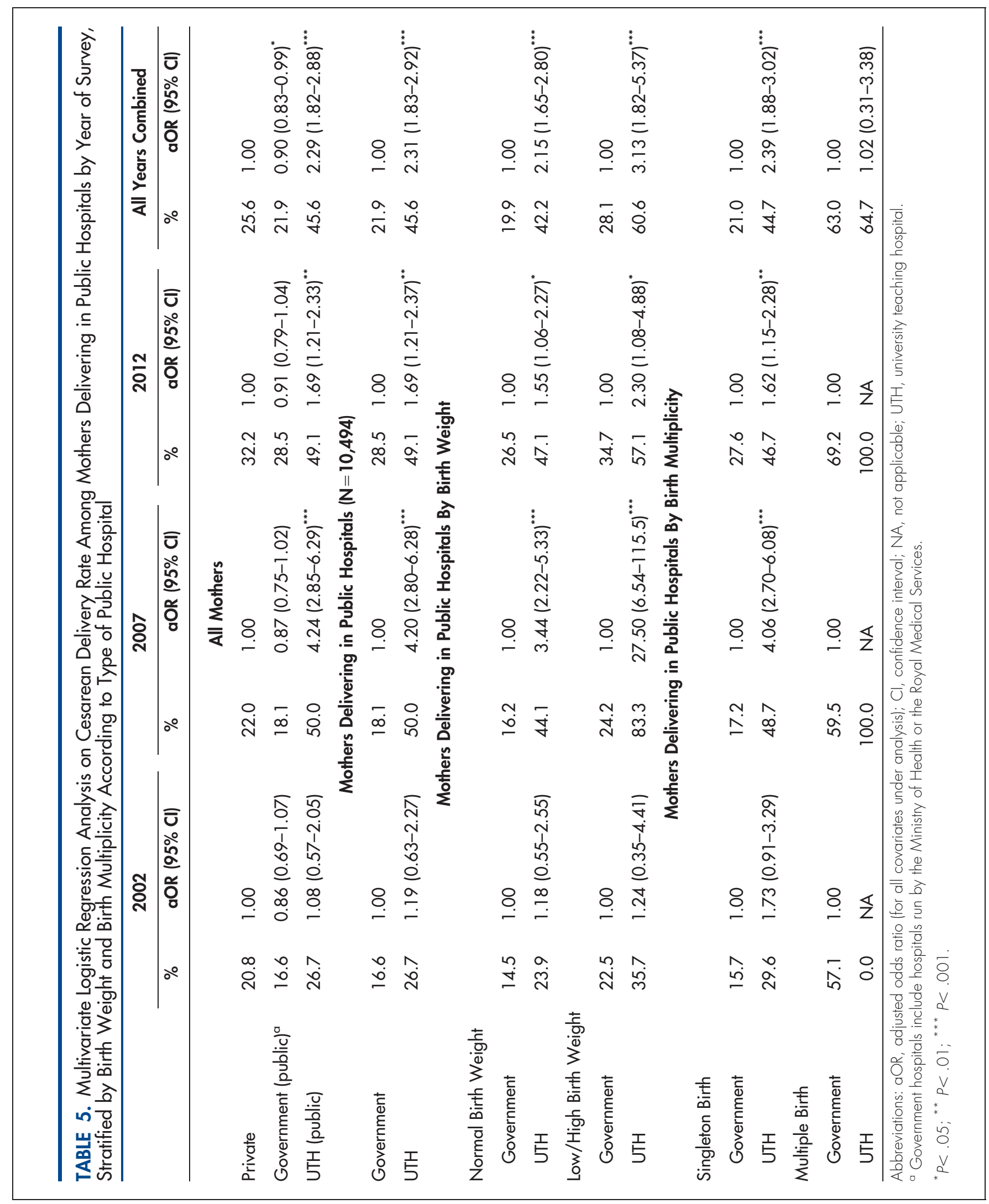


and 2.31 times higher than in government hospitals $(P<.001)$. Moreover, the odds of performing cesarean deliveries for low-risk groups-mothers of normal birth weight babies (aOR $=2.15,95 \%$ $\mathrm{CI}=1.65-2.80)$ and singletons $(\mathrm{aOR}=2.39,95 \%$ $\mathrm{CI}=1.88-3.02$ ) - was higher in UTHs than in governmental hospitals, whereas there was no significant difference in the cesarean delivery rate for multiple births between these hospital types.

Table 6 shows logistic regression analysis on the cesarean delivery rate after combining the 3 datasets. Employed mothers were significantly more likely than unemployed mothers to undergo cesarean delivery $(\mathrm{aOR}=1.34$, 95\% CI $=1.19-1.51 ; \quad P<.001)$. The odds of undergoing cesarean delivery increased linearly and significantly with increasing wealth and mother's age at first birth. Mothers with only 1 child had higher likelihood of cesarean delivery compared with those with 2 or $\geq 3$ children. Low/high birth weight infants also were more likely to have undergone cesareans. However, the strongest predictor that was associated with cesarean delivery was multiple births $(\mathrm{aOR}=5.60,95 \% \mathrm{CI}=4.20-7.09 ; P<.001)$.

\section{DISCUSSION}

This study shows that in Jordan the cesarean delivery rate has increased steadily over the past decade by two-thirds, from $18 \%$ in 2002 to $30 \%$ in 2012 , and was double the maximum population-based rate of $15 \%$ recommended by WHO. ${ }^{10}$ In Jordan, 99\% of deliveries occur in hospitals ${ }^{14}$; thus, the cesarean delivery rates reported in the JPHFS (on which this study is based) reflect population-level rates since virtually all deliveries occur in facilities.

A similar study analyzing nationally representative population survey data from Jordan between 1990 and 2002 reported that the cesarean delivery rate was $8.5 \%$ in 1990 and $12.9 \%$ in $1997 .{ }^{12}$ In the current study, the 2012 cesarean delivery rate of $30.3 \%$ is 3.6 times higher than the 1990 rate of $8.5 \% .^{12}$ This increase is in line with consistent global increases in the cesarean delivery rate. ${ }^{21}$ Some of the increase may be justified, for example, due to better access to maternal health services ${ }^{12}$ and delayed age at marriage resulting in advanced age at birth, which may be associated with adverse pregnancy outcomes. ${ }^{22,23}$ However, the sizeable increases suggest that many cesarean deliveries might occur without any, or on questionable, medical indications.
Globally there has been an increase in demand for elective cesarean delivery. An estimated $4 \%$ to $18 \%$ of all cesarean deliveries worldwide are requested by mothers. ${ }^{24}$ In this study, from 2002 to 2012 , the cesarean delivery rate in births that were likely low risk increased significantly over time after controlling for potentially confounding factors-among normal birth weight infants by $93 \%$ and among singletons by $92 \%$.

After combining all 3 datasets and adjusting for all variables under analysis, the findings revealed that, on average, mothers who were employed had higher odds of cesarean delivery than unemployed mothers, and the cesarean delivery rate increased linearly with increasing wealth-both indicators of better economic status. This is consistent with findings from a study in Nepal. ${ }^{20}$ Mothers with higher economic status have a better chance of affording the expense of such a surgical procedure.

Cesarean deliveries increased among both public and private hospitals in Jordan but more substantially in public hospitals, and particularly at UTHs. The high rate of cesareans in UTHs was associated with higher cesarean delivery rates among apparently low-risk groups (singletons, normal birth weight infants) than among highrisk groups (multiples, low/high birth weight infants). Researchers have expected cesarean deliveries to increase particularly among the private sector in Jordan over time and have speculated that the gap between public- and private-sector cesarean delivery rates may be growing. ${ }^{12}$ However, in this study, the gap narrowed from a 4.0 percentage point difference $(P=.004)$ in 2002 to 2.8 percentage points $(P=.02)$ in 2012 (Table 2$)$. The overall trend in cesarean deliveries between public and private hospitals from 2002 to 2012 was not significant $(P=.53)$. This new finding differs from what was previously reported in Jordan. ${ }^{12}$

In Jordan, there are 2 UTHs: the UTH of the University of Jordan and the King Abdullah University Hospital (KAUH) of the Jordan University of Science and Technology. A number of factors could potentially explain the higher rate of cesarean deliveries in UTHs in Jordan. First, the KAUH, which is the largest UTH, opened to the public in November 2002 and dramatically increased access to advanced medical procedures, including cesarean deliveries, for a large segment of the Jordanian population, specifically for those living in rural areas. In addition, the government initiated a health reform agenda in 2005, which

\section{The current cesarean delivery rate of $30 \%$ in Jordan is double the threshold that WHO considers reasonable.}


TABLE 6. Logistic Regression Analysis on Cesarean Delivery Rate by Background Characteristics, Among All Mothers From All Survey Datasets (2002-2012)

OR $(95 \% \mathrm{Cl})$

Age, $y$

$$
\begin{array}{r}
15-19 \\
20-24 \\
25-29
\end{array}
$$$$
\geq 30
$$

Place of Residence

Urban

Rural

Geographic Region

Central

North

South

Mother's Education

No education

Primary

Secondary

Higher

Husband's Education

No education

Primary

Secondary

Higher

Employment

Unemployed

Employed

Place of Delivery

Public sector

Private sector
1.00

$0.85(0.63-1.14)$

1.01 (0.80-1.42)

$1.47(1.11-1.94)^{* *}$

1.00

$0.90(0.82-0.99)^{*}$

1.00

$0.87(0.80-0.94)^{* *}$

1.02 (0. 90-1.16)

1.00

$1.41(1.08-1.85)^{*}$

1.01 (0.80-1.29)

$1.11(0.87-1.42)$

1.00

$1.14(0.82-1.59)$

$1.02(0.74-1.39)$

$1.22(0.89-1.68)$

1.00

$1.58(1.43-1.75)^{* * *}$

1.00

$1.17(1.08-1.26)^{* * *}$
aOR $(95 \% \mathrm{Cl})$

1.00

$0.82(0.60-1.12)$

$0.97(0.72-1.31)$

$1.05(0.78-1.41)$

1.00

$0.96(0.86-1.07)$

1.00

$0.91(0.83-0.99)^{*}$

1.03 (0.99-1.18)

1.00

$1.33(1.00-1.78)^{*}$

$0.96(0.73-1.25)$

$0.79(0.60-1.06)$

1.00

1.21 (0.84-1.73)

$1.16(0.81-1.65)$

$1.17(0.81-1.68)$

1.00

$1.34(1.19-1.51)^{* * *}$

1.00

$1.04(0.95-1.14)$ 
TABLE 6 (continued).

\begin{tabular}{|c|c|c|}
\hline & OR $(95 \% \mathrm{Cl})$ & aOR $(95 \% \mathrm{Cl})$ \\
\hline \multicolumn{3}{|l|}{ Wealth Index } \\
\hline Poorest & 1.00 & 1.00 \\
\hline Poorer & $0.94(0.84-1.05)$ & $0.94(0.84-1.06)$ \\
\hline Middle & $1.20(1.07-1.34)^{* * *}$ & $1.27(1.13-1.43)^{* * *}$ \\
\hline Richer & $1.30(1.16-1.45)^{* * *}$ & $1.32(1.16-1.51)^{* * *}$ \\
\hline Richest & $1.47(1.30-1.65)^{* * *}$ & $1.39(1.20-1.62)^{* * *}$ \\
\hline \multicolumn{3}{|l|}{ Parity in Last 5 years } \\
\hline 1 & 1.00 & 1.00 \\
\hline 2 & $0.86(0.79-0.93)^{* * *}$ & $0.81(0.75-0.88)^{* * *}$ \\
\hline$\geq 3$ & $1.04(0.90-1.18)$ & $0.82(0.70-0.95)^{*}$ \\
\hline \multicolumn{3}{|l|}{ Age at First Birth, $y$} \\
\hline $12-18$ & 1.00 & 1.00 \\
\hline $19-24$ & $1.10(0.98-1.22)$ & $1.14(1.02-1.28)^{*}$ \\
\hline $25-30$ & $1.72(1.52-1.94)^{* * *}$ & $1.75(1.52-2.01)^{* * *}$ \\
\hline$>30$ & $4.69(3.93-5.61)^{* * *}$ & $4.58(3.77-5.55)^{* * *}$ \\
\hline \multicolumn{3}{|l|}{ Birth Weight, g } \\
\hline Normal (2500-3999) & 1.00 & 1.00 \\
\hline Low/High $(<2500$ or $\geq 4000)$ & $1.55(1.43-1.68)^{* * *}$ & $1.53(1.40-1.66)^{* * *}$ \\
\hline \multicolumn{3}{|l|}{ Birth Multiplicity } \\
\hline Singleton birth & 1.00 & 1.00 \\
\hline Multiple birth & $5.47(4.38-6.82)^{* * *}$ & $5.60(4.20-7.09)^{* * *}$ \\
\hline
\end{tabular}

Abbreviations: $a O R$, adjusted odds ratio (for all covariates under analysis); $\mathrm{Cl}$, confidence interval; $\mathrm{OR}$, odds ratio.

${ }^{*} P<.05 ;{ }^{* *} P<.01 ;{ }^{* * *} P<.001$.

included improving health insurance coverage, that could have increased access to government hospitals. ${ }^{25}$ Finally, gynecology and obstetrics residents at UTHs may be more inclined to perform cesarean deliveries for the sake of practicing the surgical procedure, potentially increasing the rate of elective cesareans.

This study used data from population-based surveys that are usually conducted every 5 years. Collecting and monitoring such data in routine health information systems (RHIS) on a more regular basis (for example, annually or semiannually) could help policy makers and health professionals develop and enforce strategies to control the increase in the cesarean delivery rate, particularly cesarean deliveries without any medical indication.
A number of clinical, psychosocial, and A number of structural strategies have been used to reduce structural the likelihood of cesarean deliveries, even among strategies have those who may have a medical indication. ${ }^{26}$ For been shown to be example, a systematic review demonstrated that effective in external cephalic version (a procedure used to turn the fetus from a breech or transverse position into a vertex, or head-down, position before labor reducing cesarean deliveries. 
cesarean deliveries and advantages of vaginal delivery are also urgently needed to halt the steady increase in the cesarean delivery rate. Health professionals should give mothers full information about risks associated with cesarean delivery. Other interventions, such as midwifery training and education and establishment of birthing centers, could also help encourage mothers to deliver vaginally.

\section{Strengths and Limitations}

This study has 3 major strengths. First, analysis was based on data collected from nationally representative samples by accredited and reliable official entities using comparable sampling procedure and inclusion criteria. Second, the probability of recall bias is low since women who had a cesarean delivery would not easily forget the mode of delivery given its surgical nature, particularly for the last birth. A recent study showed that DHS data on cesarean deliveries are sufficiently reliable for national and global monitoring purposes. ${ }^{27}$ Third, stratification according to the type of hospital provided more insights about the substantial contribution of UTHs to the rising cesarean delivery rate in Jordan.

Limitations include that samples were collected through a cross-sectional design that limits the causality pathway with regard to the drivers of increased cesarean delivery rates and that the data did not include information about whether the cesarean deliveries were performed under medical indications or based solely on maternal demand. Instead, this study used only surrogate markers of what could potentially have been births at low or high risk of medically necessary cesarean delivery.

\section{CONCLUSION}

The cesarean delivery rate increased in Jordan from 2002 to 2012; the last survey in 2012 showed that the rate was double the maximum threshold recommended by WHO. The cesarean rate was higher among apparently low-risk mothers, and was particularly higher at UTHs than in private or government hospitals, which suggests that many cesarean deliveries may have been performed without medical indications. Delayed maternal age at first birth, low/high birth weights, multiple births, employment of mothers, and greater wealth were the main predictors of cesarean delivery in Jordan. More vigilant monitoring is needed to reduce unnecessary cesarean deliveries in what appear to be low-risk mothers, and in those delivering at UTHs in particular.

Acknowledgments: The author extends his great appreciation to his direct supervisor, Prof. Keiko Nakamura, Head, Department of International Health and Medicine, Tokyo Medical and Dental University, Japan, for her guidance and thoughtful insights.

Competing Interests: None declared.

\section{REFERENCES}

1. Subedi S. Rising rate of cesarean section - a year review. J Nobel Med Coll. 2012;2:72-76. Available from: www.nepjol. info/index.php/JoNMC/article/download/7303/5919

2. Villar J, Valladares E, Wojdyla D, Zavaleta N, Carroli G, Velazco A, et al; WHO 2005 global survey on maternal and perinatal health research group. Cesarean delivery rates and pregnancy outcomes: the $2005 \mathrm{WHO}$ global survey on maternal and perinatal health in Latin America. Lancet. 2006;367(9525):1819-1829. CrossRef. Medline

3. Shah A, Fawole B, M'imunya JM, Amokrane F, Nafiou I, Wolomby JJ, et al. Cesarean delivery outcomes from the WHO global survey on maternal and perinatal health in Africa. Int $J$ Gynaecol Obstet. 2009;107(3):191-197. CrossRef. Medline

4. World Health Organization (WHO). Cesarean section without medical indication increases risk of short-term adverse outcomes for mothers. Geneva: WHO; 2010. Available from: http:// whqlibdoc.who.int/hq/2010/WHO_RHR_HRP_10.20_eng.pdf.

5. Souza JP, Gülmezoglu A, Lumbiganon P, Laopaiboon M, Carroli $G$, Fawole B, et al. Cesarean section without medical indications is associated with an increased risk of adverse short-term maternal outcomes: the 2004-2008 WHO Global Survey on Maternal and Perinatal Health. BMC Med. 2010;10:8:71. CrossRef. Medline

6. Villar J, Carroli G, Zavaleta N, Donner A, Wojdyla D, Fuandes A, et al; World Health Organization 2005 Global Survey on Maternal and Perinatal Health Research Group. Maternal and neonatal individual risks and benefits associated with cesarean delivery: multicentre prospective study. BMJ. 2007;335(7628):1025-1029. CrossRef. Medline

7. Kennare R, Tucker G, Heard A, Chan A. Risks of adverse outcomes in the next birth after a first cesarean delivery. Obstet Gynecol. 2007;109(2 Pt 1):270-276. CrossRef. Medline

8. Daltveit AK, Tollånes MC, Pihlstrøm H, Irgens LM. Cesarean delivery and subsequent pregnancies. Obstet Gynecol. 2008; 111 (6):1327-1334. CrossRef. Medline

9. Allen VM, O'Connell CM, Farrell SA, Baskett TF. Economic implications of method of delivery. Am J Obstet Gynecol. 2005;193(1):192-197. CrossRef. Medline

10. Appropriate technology for birth. Lancet. 1985;2(8452):436437. CrossRef. Medline

11. Gibbons L, Belizan JM, Laver JA, Betran AP, Merialdi M, Althabe F. Inequities in the use of cesarean section deliveries in the world. Am J Obstet Gynecol. 2012;206(4):331.e1, 331.e19. CrossRef. Medline

12. Khawaja M, Al-Nsour M. Trends in the prevalence and determinants of cesarean section delivery in Jordan: evidence from three demographic and health surveys, 1990-2002. World Health Popul. 2007;9(4):17-28. CrossRef. Medline

13. World Health Organization (WHO), Regional Health Systems Observatory. Health systems profile: Jordan. Cairo: WHO, Regional Office for the Eastern Mediterranean (EMRO); 2006. Available from: http://gis.emro.who.int/ HealthSystemObservatory/PDF/Jordan/Full\%20Profile.pdf 
14. Department of Statistics [Jordan]; ICF International. Jordan population and family health survey 2012. Calverton (MD): ICF International; 2013. Available from: http://dhsprogram.com/ pubs/pdf/FR282/FR282.pdf

15. World Bank Open Data [Internet]. Washington (DC): World Bank. c2014. Maternal mortality ratio (modeled estimate, per 100,000 live births); [cited 2014 Apr 11]; [about 10 screens]. Available from: hitp://data.worldbank.org/indicator/SH.STA.MMRT

16. World Bank Open Data [Internet]. Washington (DC): World Bank. c2014. Mortality rate, neonatal (per 1,000 live births); [cited 2014 Apr 11]; [about 10 screens]. Available from: http:// data.worldbank.org/indicator/SH.DYN.NMRT

17. Filmer $D$, Pritchett $L H$. Estimating wealth effects without expenditure data-or tears: an application to educational enrollments in states of India. Demography. 2001;38(1):115-132. Medline

18. Al Busaidi I, Al-Farsi Y, Ganguly S, Gowri V. Obstetric and nonobstetric risk factors for cesarean section in oman. Oman Med J. 2012;27(6):478-481. CrossRef. Medline

19. Gomes UA, Silva AA, Bettiol H, Barbieri MA. Risk factors for the increasing cesarean section rate in Southeast Brazil: a comparison of two birth cohorts, 1978-1979 and 1994. Int J Epidemiol. 1999;28(4):687-694. CrossRef. Medline

20. Prakash KC, Neupane S. Cesarean deliveries among Nepalese mothers: changes over time 2001-2011 and determinants. Arch Gynecol Obstet. 2014;289(2):421-427. CrossRef. Medline
21. O'Leary CM, de Klerk N, Keogh J, et al. Trends in mode of delivery during 1984-2003: can they be explained by pregnancy and delivery complications? BJOG. 2007;114(7):855-864. CrossRef. Medline

22. Cleary-Goldman J,, Vidaver J, Ball RH, Nyberg DA, Comstock $\mathrm{CH}$, et al. Impact of maternal age on obstetric outcome. Obstet Gynecol. 2005 May; 105(5 Pt 1):983-90. Medline

23. Maharlouei N, Moalaee M, Ajdari S, Zarei M, Lankarani KB. Cesarean delivery in south-western Iran: trends and determinants in a community-based survey. Med Princ Pract. 2013;22(2):184-188. CrossRef. Medline

24. National Institutes of Health state-of-the-science conference statement: Cesarean delivery on maternal request March 2729, 2006. Obstet Gynecol 2006;107(6):1386-1397. Medline

25. Library of Congress [US], Federal Research Division. Country profile: Jordan. Washington (DC): Library of Congress; 2006. Available from: http://lcweb2.loc.gov/frd/cs/profiles/Jordan. pdf.

26. Walker R, Turnbull D, Wilkinson C. Strategies to address global cesarean section rates: a review of the evidence. Birth. 2002;29(1):28-39. CrossRef. Medline

27. Stanton CK, Dubourg D, De Brouwere V, Pujades $M$, Ronsmans C. Reliability of data on cesarean sections in developing countries. Bull World Health Organ. 2005;83(6):449-455. Medline

\section{Peer Reviewed}

Received: 2014 Feb 10; Accepted: 2014 Apr 21

Cite this article as: Al Rifai R. Rising cesarean deliveries among apparently low-risk mothers at university teaching hospitals in Jordan: analysis of population survey data, 2002-2012. Glob Health Sci Pract. 2014;2(2):195-209. http://dx.doi.org/10.9745/GHSP-D-14-00027

(๑) Al Rifai. This is an open-access article distributed under the terms of the Creative Commons Attribution License, which permits unrestricted use, distribution, and reproduction in any medium, provided the original author and source are properly cited. To view a copy of the license, visit http://creativecommons.org/licenses/by/3.0/ 